\title{
Visões sobre o envelhecer: o distanciamento e a proximidade da velhice com a grande cidade*
}

\section{Views about aging: old age's distancing from and nearness to the big town}

\author{
Leonardo Jose Costa de Lima', Nadia Dumara Ruiz Silveira²
}

LIMA, L. J. C. de; SILVEIRA, N. D. R. Visões sobre o envelhecer: o distanciamento e a proximidade da velhice com a grande cidade. Rev. Ter. Ocup. Univ. São Paulo, v. 20, n. 3, p. 171-179, set./ dez. 2009.

RESUMO: Os processos de globalização e urbanização contemporâneos e a necessidade de caracterização do perfil e necessidades do crescente número de idosos em todo o mundo têm impulsionado recentes investigações cientificas interdisciplinares. Este trabalho busca oferecer contribuições no entendimento destas questões, com enfoque no idoso morador da cidade de São Paulo. Apresenta parte dos resultados de pesquisa qualitativa documental realizada com base na análise do conteúdo de obras de pintura e dos registros de verbalizações de idosos participantes de grupo do Programa Permanente Composições Artísticas e Terapia Ocupacional/ PACTO, no ano de 2001. Embasado num campo conceitual de referência interdisciplinar, considerando-se teórica e praticamente, as interfaces da Terapia Ocupacional, Arte e Gerontologia oferece uma reflexão sobre a realidade apontada por estes idosos: o dimensionamento do próprio envelhecimento biológico se apresenta aliado a uma consciência da realidade em que vivem, à necessidade de manutenção das relações de afeto, solidariedade e de cuidados entre as pessoas que envelhecem.

DESCRITORES: Idoso. Arte. Processos grupais. Terapia ocupacional.

\footnotetext{
* Artigo é parte integrante de dissertação de Mestrado apresentada no Programa de Estudos Pós-graduados em Gerontologia, PUC/SP em 2005.

${ }^{1}$ Docente do curso de Terapia Ocupacional da Universidade de Sorocaba.

${ }^{2}$ Docente do Programa de Estudos Pós-graduados em Gerontologia, PUC/SP.

Endereço para correspondência: R. Gonçalves Dias, 845. Ap.73, Bl. 4 .Sorocaba, SP. CEP: 018081-040. E-mail: leonardo.lima@prof. uniso.br
} 


\section{INTRODUÇÃO: o trabalho e seu contexto}

s reflexões apresentadas nesse artigo fazem
parte dos resultados obtidos no trabalho
de pesquisa apresentado no programa de Estudos Pós-graduados em Gerontologia da Pontifícia Universidade Católica de São Paulo, nível mestrado, em 2005 e apontam para novas interpretações e compreensões do envelhecimento urbano contemporâneo e também para possibilidades de reinvenção contínua da prática grupal com idosos na comunidade. $\mathrm{O}$ estudo caracterizase como uma pesquisa qualitativa, que aborda a temática do envelhecimento contemporâneo nas grandes cidades focalizando a experiência de um dos grupos do Programa Permanente Composições Artísticas e Terapia Ocupacional - PACTO $^{1}$. Este grupo, composto em sua grande maioria por pessoas com mais de 60 anos, trabalhou entre os anos de 1998 e 2004 em encontros grupais semanais realizados nos laboratórios de atividades localizados na Universidade de São Paulo.

A proposta do trabalho, desenvolvida na interface arte/saúde, visava a promoção de um envelhecimento com qualidade de vida no que se refere aos aspectos biopsicossociais, a prevenção e melhora de fatores de ordem biológica e psicossocial, ampliando, assim, a ação dos idosos no seu meio. Buscava-se, dessa forma, facilitar a inclusão do sujeito que envelhece em redes de troca e interação social.

Participaram deste grupo vinte e três idosos, cinco técnicos, um coordenador terapeuta ocupacional, três estagiárias do quarto ano do curso de Terapia Ocupacional da FMUSP (duas no primeiro e uma no segundo semestre), uma bolsista, terapeuta ocupacional do Curso de especialização lato sensu Práxis Artística e Terapêutica - Interfaces da Arte e da Saúde, da mesma instituição de ensino e dois convidados.

O grupo tinha como proposta a realização de atividades em dois momentos distintos e complementares a cada encontro: no primeiro, foram desenvolvidas as atividades corporais e a seguir as artísticas plásticas, intercaladas por uma pausa para um café e lanche coletivo.

Utilizando-se de Abordagens Artísticas - Plásticas (Pintura e Modelagem em Argila) e Corporais (Relaxamento, Massagem, Automassagem, Dança e Expressão Corporal)
- a proposta incluiu atividades de autoconhecimento e integração grupal, prevenção de agravos à saúde, construção de novas linguagens e inclusão social.

Em especial, as atividades artísticas mostram-se como um canal eficiente na diminuição de agravos à saúde, pois desenvolvem possibilidades de instauração de estado potencial de criação e autoconhecimento, possibilitando processualidades próprias nas quais são fundamentais a comunicação e o diálogo com novas formas e configurações que facilitam a criação de estratégias voltadas para o autocuidado.

As atividades de cunho artístico e cultural tinham como referência as queixas de quem vive nos grandes centros urbanos como São Paulo, onde a solidão, a depressão e a falta de atividades de integração social, que potencializem a criatividade, autonomia e independência, são freqüentes.

As produções pictóricas que emergiram nesses encontros no ano de 2001, associadas às verbalizações sobre vivências de envelhecimento, possibilitaram análise das representações sobre a vida urbana e a identificação das visões destes idosos sobre o envelhecer na grande cidade e de suas propostas para um envelhecimento saudável.

A pesquisa realizada se baseou em documentos como fonte dos dados, considerados no processo analítico. Seguindo a proposição de Lüdke \& André (1986), entendemos, por documentos quaisquer materiais escritos que possam ser usados como fonte de informação para o tema pesquisado. Segundo os autores, os documentos podem ser utilizados de forma isolada ou combinados com outros tipos de documentação, escolhidos segundo alguns propósitos, idéias ou hipóteses que guiam sua seleção na realização de estudos científicos.

Em nossa pesquisa tomamos como documentos os diários de registro dos grupos, roteiros, arquivos e prontuários do PACTO e fotografias das produções de pintura realizadas pelos idosos nos ateliês e apresentadas em exposição realizada na festa de encerramento do grupo no final do ano de 2001.

Quanto à importância da análise das obras de pintura, destacamos inicialmente, de acordo com Manguel, o significado das mesmas ao serem interpretadas:

As imagens visuais, que existem no mundo dos que podem ver, são como um rolo que se desdobra continuamente. São capturadas pela visão e realçadas ou

\footnotetext{
${ }^{1}$ Trata-se do primeiro grupo de adultos do Programa Permanente Composições Artísticas e Terapia Ocupacional (PACTO), atividade de extensão do Curso de Terapia Ocupacional da Universidade de São Paulo. Mais detalhes sobre o programa pode ser visto em: CANGUÇU, D. F., et al. O Programa Permanente Composições Artísticas e Terapia ocupacional (PACTO): uma proposta de atenção na interface da arte-saúde. Rev. Ter. Ocup. Univ. São Paulo, v. 11, n. 2/3, p. 45-55, maio/dez., 2000.
} 
moderadas pelos outros sentidos, imagens cujo significado (ou suposição de significado) varia constantemente, configurando uma linguagem feita de imagens traduzidas em palavras e de palavras traduzidas em imagens, por meio das quais tentamos abarcar e compreender nossa própria existência. As imagens que formam nosso mundo são símbolos, sinais, mensagens e alegorias (MANGUEL, 2001, p.21).

Assim, consideramos que as pinturas produzidas pelos participantes do grupo, nos ateliês de atividades artísticas, constituíram-se em objetos documentais importantes neste trabalho, complementando os dados apresentados nos relatos, permitindo uma leitura mais ampla dessa realidade, na medida em que consideramos que as imagens e os registros escritos ou orais oferecem informações sobre as pessoas e a realidade vivida por elas.

A seleção das obras partiu de uma pesquisa nos arquivos das obras produzidas pelo grupo, fotografadas e organizadas em um pequeno álbum, pelas estagiárias. O principal critério de seleção foi a relação das obras com a temática desenvolvida no PACTO em 2001: "O cotidiano em São Paulo". O conjunto de obras selecionadas inclui um exemplar de cada participante.

Para analisarmos a mensagem das imagens selecionadas, inicialmente realizamos uma descrição das obras, ou seja, a transcodificação das percepções visuais para a linguagem verbal; em seguida foi feita uma distinção dos diversos tipos de significados, globais e singulares dessas mensagens.

Joly (1996) constata que as imagens apresentadas em obras visuais, como a pintura, não podem ser confundidas com a analogia no sentido de semelhança entre a representação e o objeto, visto que não são constituídas apenas de figuração, mas integram diferentes materiais entre si para constituir uma mensagem visual. A analogia perceptiva se dá ao decifrarmos as imagens, considerando que os elementos que nelas identificamos são unidades culturais, partes da realidade vivida pelo seu autor.

Ao se referir aos diferentes signos que compõem as mensagens visuais de uma obra, a autora destaca que:

Dentro da mensagem visual, vamos distinguir os signos figurativos ou icônicos, que, de modo codificado, dão uma impressão de semelhança com a realidade jogando com a analogia perceptiva e com os códigos de representação herdados da tradição de representação ocidental. Finalmente, vamos designar com o termo signos plásticos os componentes propriamente plásticos da imagem, como a cor, as formas, a composição e a textura Os signos icônicos e os signos plásticos são então considerados como signos visuais, ao mesmo tempo distintos e complementares (JOLY, 1996, p. 75).

Esses signos de que fala a autora irão compor parte da mensagem visual global: a mensagem icônica e a mensagem plástica. Ao se referir ao outro componente da imagem visual, a mensagem lingüística, considerada como palavras ou texto presentes nas obras, a autora entende como parte da significação da mensagem, distinguindo-a de seu suporte: uma imagem publicitária, uma pintura ou um cartaz.

A leitura e interpretação das significações plásticas e icônicas, que compõem a mensagem plástica das obras selecionadas incluíram: a analise das imagens representadas, o suporte, as dimensões, o enquadramento, a composição, as formas, cores, iluminação e a textura das pinturas apresentadas.

Para realizarmos a análise das mensagens lingüísticas, foram utilizados os princípios gerais da retórica proposto por Joly (1996) para articular os significantes e significados das imagens.

A síntese das significações das mensagens plásticas, icônicas e lingüísticas possibilitou a compreensão de uma mensagem global, pois os diversos componentes da imagem "[...] têm o mérito de colocar em evidência a heterogeneidade da mesma. Seus materiais são múltiplos e articulam suas significações específicas umas às outras para produzir a mensagem global" (JOLY, 1996, p.74).

Consideramos, como Manguel (2001) que "Nenhuma narrativa suscitada por uma imagem é definitiva ou exclusiva, e as medidas para aferir a sua justeza variam segundo as mesmas circunstâncias que dão origem à própria narrativa" (MANGUEL, 2001, p.28). Assim sendo, a leitura das imagens das pinturas levou em conta suas mensagens, significados, formas e conteúdos que expressassem diferentes tipos de experiências e conceitos elaborados por seus criadores em uma relação estreita com o mundo e os outros homens.

A pesquisa, através da análise dos documentos coletados e selecionados oferece subsídios para um melhor desempenho de profissionais de gerontologia, em especial os terapeutas ocupacionais que trabalham na interface das áreas da saúde e artes e aponta para possíveis redimensionamentos de propostas institucionais de intervenção voltadas para idosos moradores de centros urbanos e que buscam um envelhecimento com qualidade.

\section{Velhice e qualidade de vida na grande cidade}

Segundo dados do Instituto Brasileiro de Geografia e Estatística (IBGE, 2002) atualmente $80 \%$ da população idosa brasileira reside em centros urbanos. Os idosos que vivem o cotidiano das grandes cidades enfrentam condições de vida paradoxais, pois as necessárias adaptações às perdas funcionais da envelhescência se confrontam com 
as imposições e contradições do cotidiano urbano impostas pela vida contemporânea.

Novos paradigmas de atendimento em gerontologia emergem dessa realidade, trazendo a desospitalização e a criação de instâncias intermediárias de assistência à saúde, hospitais-dia, centros-dia e centros de convivência, como propostas para o cuidado com a preservação da saúde e qualidade de vida da população idosa. Segundo Veras (2001, p. 78), a recuperação e/ou manutenção da qualidade de vida é, cada vez mais, um dos objetivos centrais das abordagens gerontológicas.

As atividades físicas grupais, sociais e culturais têm sido estudadas como promotoras da melhoria de aspectos psíquicos e físicos dos idosos, vindo ao encontro das principais queixas dessa população quais sejam: o abandono, a solidão, a depressão e a inatividade. Programas e projetos contemporâneos, de cunho interdisciplinar, voltados para idosos da cidade de São Paulo e baseados em concepções solidárias e criativas do homem são propostos principalmente pelas áreas das ciências sociais e humanas.

Destacamos principalmente os realizados no campo das artes, da educação e da saúde, que têm instaurado espaços de experimentação que consideram as singularidades das pessoas e suas histórias de vida e tem como pontos convergentes a utilização do recurso artístico como forma de alcançar e manter a qualidade de vida dos que envelhecem.

Como exemplo deste trabalho temos, na cidade de São Paulo, o Programa Permanente Composições Artísticas e Terapia Ocupacional (PACTO) que em conjunto com as alternativas oferecidas por instituições privadas e pelo poder público estadual e municipal, apresenta-se como uma experiência de sucesso no oferecimento, através de atividades artísticas e corporais, de um espaço para a convivência e reflexão sobre o envelhecimento bem sucedido e com qualidade.

O tema "qualidade de vida" tem sido, hoje, um dos mais referidos por técnicos da saúde, educadores, artistas, ecologistas, sociólogos, psicólogos, engenheiros, fazendo parte, até mesmo, de campanhas publicitárias de venda de bens de consumo.

Para Simões "qualidade é a palavra presente na contemporaneidade, a qual pode ser articulada com a idéia de condição, de função, de atitude, de posição ou ter outro sentido em conseqüência da abrangência que esse tema possui".

Autores da área da saúde, como Paschoal (1994), associam qualidade de vida no envelhecimento à autonomia e independência em atividades da vida diária. Em seus estudos o autor afirma que a manutenção da qualidade excelente de vida no envelhecimento pode ser avaliada pela manutenção da autonomia, entendida como a possibilidade de "ter sua própria lei" (p.316) e independência, conceito relativizado e pluralizado que, para o autor, se refere a "nãonecessidade de ajuda de outras pessoas no desempenho de atividades do cotidiano" (p.316) nas AAVDs (Atividades Avançadas da Vida Diária).

O autor, citando Reuben e Solomon (1989), refere que as AAVDs seriam aquelas atividades que são "[...] dependentes de vontade, de desejo e, principalmente, de motivação, especificas para cada indivíduo e influenciadas por forças culturais e sociais" (p. 319). Seriam exemplos dessas atividades: a prática de esportes, pintar, cantar, dançar, tocar algum instrumento, viajar, participar de algum serviço voluntário, clubes ou de atividade política.

Consideramos que as propostas existentes em grandes metrópoles como São Paulo, como por exemplo, o Programa Lazer com Arte para a Terceira Idade do Museu de Arte Contemporânea da Universidade de São Paulo, têm aproximado profissionais de diversas áreas de atuação, como artes, saúde e educação, reforçando um dos princípios fundamentais da gerontologia que é produzir conhecimentos e metodologias através de ações que sejam interdisciplinares.

Castro (2003) destaca que, esse desafio tem sido enfrentado por diversos profissionais contemporâneos como artistas, arte-educadores, psicólogos, terapeutas ocupacionais e educadores, que se relacionam de diferentes formas e em diferentes momentos com a questão. Como diz a autora, "cada particularidade pensada e vivenciada num desses campos pode produzir uma ressonância nos outros ou ainda, percursos já trilhados podem sinalizar novas trajetórias, novos entendimentos" (p. 5).

\section{O distanciamento e a proximidade da velhice com a cidade: projeções e subjetividades}

Podemos analisar a observação do cotidiano da cidade a partir dos planos de enquadramento apresentados pelas obras de pintura produzidas pelos idosos do PACTO, associando-as às suas verbalizações.

As cenas que referem um distanciamento dos fatos se apresentam em visões panorâmicas de determinada situação, na qual o artista e o expectador são colocados em uma posição de observadores à distância do que se desenrola a sua frente.

Essas representações marcam a idéia de voyeurismo, isolamento e necessidade de se proteger das situações apresentadas. Essas obras trazem uma visão analítica dessa realidade da qual o idoso faz parte, mas se mantêm a certa distância, revelando uma noção crítica, embora não se 
aproxime e não a vivencie como agente transformador.

$\mathrm{O}$ isolamento e não-participação nessa realidade é também referido pelos idosos do grupo estudado, que muitas vezes verbalizam "Sinto solidão" ao falarem de seus sentimentos cotidianos.

Essa experiência de distanciamento e solidão está relacionada ao que Wilhein (1997) analisa sobre o espaço público da cidade de São Paulo. Segundo o autor, esses espaços vêm, gradualmente, constituindo-se como "um espaço do outro, um espaço de ninguém", e à medida que o idoso se afasta desse espaço público, passa a ocupar uma posição de observador distante, não-participativo, isolandose em sua residência e vida privada.

Consideramos que o afastamento do idoso dessas situações cotidianas se refere, também, a sua condição de excluído do mercado de trabalho, principalmente devido à aposentadoria, vivida pela maioria dos idosos do grupo estudado como um marco transformador em sua vida.

Ao relatarem que têm "obstáculos à realização dos desejos", os participantes do grupo referem-se a uma sociedade que não integra o idoso em seu cotidiano, principalmente em seu mercado de trabalho.

Observamos também, nas pinturas, uma oposição entre cenas urbanas e rurais sendo que a organização das composições sugere que a parte central da obra, principal foco de atenção do expectador, é ocupada por imagens predominantemente urbanas, e as imagens que ocupam as laterais remetem a uma lembrança ou revelação de uma origem rural desses idosos. As grandes cidades são marcadas pelo expressivo número de imigrantes e migrantes, que configura uma de suas principais características: o ser cosmopolita.

Nessas composições podemos observar uma representação temporal: o passado no campo, apresentado em cores quentes e formas orgânicas, e o presente urbano apresentado em cores frias e geometrização. Não há pessoas representadas nessas composições e as imagens levam o espectador a perceber que o centro da visão/pensamento contemporâneo está focalizado em novas informações, que cada vez mais substituem as anteriores, consideradas antigas ou obsoletas.

A frieza da cidade, representada em cores frias como os azuis, substitui o calor do campo, representado em tons de amarelo e vermelho. Temos, assim, uma referência à mudança de valores sociais de uma época para outra. Pode-se considerar que segundo essa visão, atualmente não há integração entre esses valores, fato que acaba por excluir o conhecimento acumulado pelos idosos nos seus anos de vida.

Por analogia, podemos nos referir à existência de um distanciamento dos valores sociais dos idosos, representados pela cena rural, dos valores dos jovens, representados pela cena urbana e uma centralização contemporânea nos novos valores e na figura da juventude como modelo de produtividade e de vida.

A necessidade ou desejo de ações que integrem essas duas realidades, pode ser observada na verbalização: "Gostei da mudança do ambiente", como uma resposta à mudança do local de realização de atividades pelas estagiárias que coordenavam o grupo nesse dia, que propuseram sua realização em ambiente externo em frente ao predio utilizado para este fim.

Em outra obra, a figura de um homem que foge, nos remete à idéia de medo e persecutoriedade da grande massa de trabalhadores/consumidores/jovens, nesse caso em especial, significando o afastamento dos idosos das atividades de trabalho com a aposentadoria. Aqui podemos observar uma mensagem que denuncia a separação entre o velho e o novo na cidade e entre o idoso e o jovem em suas vivências cotidianas.

Quanto à questão da aproximação do autor com a cena representada, as cenas apresentadas nas obras são mais focadas, em meio-closes, e trazem o expectador para dentro da ação. Muitas dessas cenas remetem às situações de violência freqüentemente vivenciadas pelas pessoas na cidade de São Paulo e captadas pelos idosos que nela vivem. Uma obra nos coloca diante de uma realidade que impacta e paralisa. A presença de um corpo humano caído de bruços no chão, e a não-identificação dessa figura, o morto do título da obra, parece nos dizer que qualquer pessoa que mora na cidade pode ser vitimada por essa violência.

A morte é tratada como conseqüência de uma das questões sociais da cidade: a violência. Essa imagem também pode deslocar o ponto de vista do expectador, pois a morte pode ser vista como realidade apresentada ao futuro de todas as pessoas, não somente aos idosos.

Ao se referirem à morte, os participantes do grupo verbalizam que: "O futuro é a morte". Essa frase pode ser entendida de duas formas. A primeira, a projeção de um futuro no qual a única coisa que pode ser esperada é a morte. Outra, que nos parece uma leitura mais adequada devido às características do grupo estudado, seria uma clareza frente

\footnotetext{
${ }^{2}$ As frases dos participantes, citadas entre aspas neste artigo, foram transcritas dos relatos escritos dos grupos, realizados pelo coordenador e estagiários do grupo estudado.
} 
à morte como mais um acontecimento da vida das pessoas. Essa clareza não é impeditiva da realização da vida, já que os participantes verbalizam, ao se referirem ao futuro: "São necessárias adaptações, vida comunitária e construção de laços de afeto" e "Amo a vida, tem dias que penso que as horas foram poucas".

Outra composição nos remete à questão da excessiva valorização da juventude nas sociedades contemporâneas, independente de sua etnia e cultura. A excessiva valorização da juventude é mostrada em um cenário surrealista e assustador, onde pessoas olham para trás, para o passado e para imagens de jovens. A obra nos remete a valorização dos jovens atuais e das lembranças do tempo de juventude pela nossa sociedade que é impeditiva da realização e exercício de uma vida mais prazeirosa pelos idosos.

Essas questões também são referidas verbalmente quando dizem: "Me sinto exposta quando brinco com os netos"; "Existe a privação do lúdico pelas pessoas"; "Há um constrangimento em exercitar o lúdico, o prazer".

Essas verbalizações indicam uma associação do lúdico e, principalmente do prazer, com a juventude e se referem também a um tipo de interdição social imposta aos idosos quanto ao exercício de atividades lúdicas e prazeirosas, interdição que, ainda segundo os participanres do grupo, "Geram obstáculos à realização dos desejos".

Uma outra obra apresenta uma mulher observando uma cena urbana. Ela se mantém em posição de isolamento e solidão. Sua roupa preta pode corresponder ao luto que podemos associar inicialmente à perda de pessoas da família, filhos ou marido, mas que também pode ser visto como a perda da juventude, que se encontra asfaltada como as ruas da grande cidade.

Essa obra pode ser considerada um alerta ao expectador quanto ao seu próprio isolamento na grande cidade, trazendo uma reflexão sobre seu futuro como envelhescente. Essa reflexão é verbalizada quando dizem que: "Aí fora ninguém ajuda ninguém".

Outra é a experiência no grupo. A configuração grupal possibilita às pessoas se relacionarem com seus processos de criação, espaço e tempo grupal, permitindo, assim, a criação artística com a articulação de representações internas e externas.

A heterogeneidade do grupo permite que se busquem novas inserções, novos regimes de responsabilidade, com respeito às singularidades e desvantagens de cada participante, entendendo-as relacionadas à perda da qualidade de vida, da qualidade das relações sociais, da satisfação de viver, ao aumento do estresse, ansiedade e baixa auto-estima, que podem ser decorrentes do processo de envelhecimento.
Outras imagens trazem também uma idéia de oposição, que sugere o paradoxo vivenciado pelas pessoas nos grandes centros urbanos: o enclausuramento dos locais de trabalho e a sensação de liberdade encontrada nos momentos de happy hour, nos quais a sensualidade e a busca pela companhia de pessoas, bebidas e lazer acontecem.

Esse paradoxo pode ser vivido pelos idosos de forma ainda mais intensa, pois a partir do momento em que eles se aposentam, deixam de ter contato diário com seus companheiros de trabalho e perdem a possibilidade de desfrutarem um dos poucos momentos de lazer com amigos, fora da família, permitido aos que vivem nas grandes cidades.

Cabe destacar, então, a importância da manutenção de espaços de encontro e convivência para os idosos que se aposentam. Esta proposta vem sendo encampada pelas associações de aposentados que procuram oferecer, além da assistência jurídica aos seus associados, encontros e eventos de lazer, procurando minimizar o isolamento social que pode ser decorrente da aposentadoria.

A organização de programas de pré-aposentadoria apresenta, através do planejamento do uso do tempo livre, decorrente da cessação das atividades de trabalho, alternativas para o uso desse tempo em projetos de atividades que não só colaboram para a continuidade de uma vida ativa, descoberta e de resgate de antigos desejos, como também favorecem a continuidade de momentos de lazer com seus pares de trabalho. Vale salientar que esses programas ainda não são rotina nas empresas e que, devido à sua grande importância para as pessoas que envelhecem, merecem ser estimulados em nossa sociedade.

A promoção de atividades sociais, tais como os bailes e encontros sociais, promovidos pelos grupos de terceira idade, abre possibilidades para a continuidade desses momentos de encontros sociais e afetivos. Cabe aqui uma ressalva: a questão de que esses espaços ainda não favorecem as trocas inter-geracionais, que ficam restritas, na maioria das vezes, a se concretizarem somente dentro do núcleo familiar.

Os participantes do grupo demonstram, também, um reconhecimento da necessidade de formação de profissionais na área da gerontologia para acompanhar as pessoas que envelhecem, ao verbalizarem a necessidade de coordenação técnica nos grupos: "Quando a atividade é realizada pelo coordenador técnico há mais segurança (...) pois fornecem apoio e tem conhecimento de anatomia, etc. (...) as intervenções do terapeuta dão uma qualidade diferente, pois tem o conhecimento técnico".

Essas verbalizações têm ressonância nas propostas de formação de profissionais em gerontologia, apontadas por 
Jordão Netto (1997), entre eles o terapeuta ocupacional, ao se referir à necessidade de formação de especialistas capacitados para auxiliar os idosos a lidar com suas possíveis limitações e a procurar novas formas, meios ou técnicas para manterem e melhorarem sua participação ativa na sociedade.

Em outra obra vemos um homem que se encontra de pé, em postura estática e com as mãos nos bolsos. Olha para cima, com semblante sério como se estivesse indagando o que se passa ao seu lado. Não há nenhuma referência à presença de outras pessoas na composição e o expectador pode vivenciar, ao mesmo tempo, uma proximidade e um distanciamento da figura humana e de seu entorno e indagar: O que preocupa esse homem? Será que ele está à espera de algo ou de alguém? Quais seriam suas preocupações e expectativas com relação aos desdobramentos dessa cena?

Ao se referirem, no grupo, sobre suas expectativas com relação ao futuro, os participantes manifestam suas dúvidas em verbalizações como: "Como enfrentar os perigos do envelhecimento?"; "No futuro quem vai cuidar da gente?". A velhice é vista como mais um enigma ou perigo que deve ser enfrentado pelas pessoas nas grandes cidades. A percepção da dependência, que os idosos vislumbram como possibilidade futura, vem acompanhada de dúvidas sobre quais serão as pessoas que os ajudarão em suas futuras necessidades, decorrentes da perda da independência, em especial, da física.

O conhecimento das possibilidades de um envelhecimento com dependências é acompanhado pela clareza de que as relações familiares e os afetos são necessários para manter uma velhice mais protegida e digna.

Uma questão relevante presente nas obras apresentadas e verbalizações referem-se à preocupação com a independência no dia-a-dia do envelhecimento. A independência do idoso é valorizada em frases como: "E bom sair sozinha para o teatro, cinema e outros passeios" e "Não aceito a dependência" e, ao mesmo tempo a possibilidade de uma futura dependência é motivo de preocupação, ao relatarem que: "Hoje tenho independência, no futuro haverá necessidade de adaptações".

Uma possível necessidade de adaptações nas rotinas diárias com o envelhecimento é reconhecida pelo grupo como forma de se manterem independentes nessa fase da vida e, apontam a família como futuro e desejável cuidadora, quando isso se fizer necessário.

Ao mesmo tempo propõem alternativas extrafamiliares para esse cuidado. Essas alternativas seriam baseadas em relações de cooperação intra-geracionais, com pessoas que fazem parte de seu círculo eletivo de afetos, "Os idosos mais independentes", em uma vida comunitária permeada por vínculos afetivos: "Deveríamos criar uma comunidade, um apoiando o outro e cada um criando projetos com suas habilidades, uma cooperativa, cada um morando no seu espaço".

A preservação da autonomia, da independência e dos vínculos afetivos, familiares e eletivos, se colocam como fatores primordiais para um bom envelhecimento futuro, demonstrando um reconhecimento e receio da possibilidade de um cuidador formal ou de um processo de asilamento.

As obras trazem a questão de um diálogo muito próximo com a realidade e com o expectador, com mensagem clara sobre os cuidados e preocupações com o futuro envelhecimento e sua qualidade, que se complementam com as verbalizações quanto às suas dúvidas e necessidades, quanto à manutenção de afetos, de trocas inter-pessoais e do contato físico acolhedor durante essa etapa de seu ciclo vital.

A importância das trocas interpessoais para se alcançar um cotidiano mais rico em possibilidades que podem ser descobertas são apontadas em frases como: "A conversa ajuda a sair do meu eu e encontrar outras coisas, realizar novas atividades", "É preciso ser um eterno aprendiz".

Esse diálogo entre questões objetivas/subjetivas da cidade e os idosos nos remete aos apontamentos de Simões (2001), ao referir que:

[...] qualidade de vida é qualidade de vivência do dia-a-dia e, no interior da terceira idade é proporcionar o início de uma caminhada, um ponto de partida, não um ponto de chegada, independentemente das perdas que o mundo adulto produtivo rentável coloca; é ir à busca dos encontros, dos incentivos, dos desafios, dos projetos, das incertezas, dos desejos e, sem dúvida, dos sonhos (p. 189).

\section{ALGUMAS CONSIDERAÇÕES}

A almejada qualidade de vida dos que envelhecem nas grandes cidades está, como nos aponta Simões (2001), aliada à obtenção e manutenção de saúde, trabalho, moradia, alimentação, informação, liberdade de atuação política, proteção contra a violência, fruição do lazer, participação em atividades físicas e motoras, convivência com outras pessoas e, principalmente, no desejo de descobrir formas para alcançar uma vida longa, prazerosa, saudável e satisfatória.

Podemos apresentar como resultados desta pesquisa que as experiências artísticas mostram-se como um caminho possibilitador de expressão e reflexão, que o idoso pode percorrer trazendo conteúdos de sua história pessoal.

As experiências vividas no grupo, com seus pares, em 
atividades artísticas, são transpostas conscientemente para seu cotidiano, como verbalizadas: "Tudo que acontece aqui eu levo como experiência para meu dia-a-dia". Essa transposição possibilita a descoberta de novas alternativas para a solução de conflitos pessoais e sociais presentes em seu dia-a-dia, pois as atividades artísticas, como parte das atividades humanas, dispõem de linguagem não-verbal e apresentam grande número de estímulos e canais de representação, expressão e simbolização como possibilidades de compensações e adaptações ao processo de envelhecimento.

A proposta do PACTO, integrando arte e corpo em processos terapêuticos ocupacionais, é potencializadora de alternativas para a manutenção da qualidade de vida excelente, conforme aponta Paschoal (1994), através do real dimensionamento das transformações físicas e sociais do envelhecimento e da participação em Atividades Avançadas da Vida Diária.

Além disso, as experiências com inúmeros materiais, técnicas e pessoas possibilitam uma mudança na rotina, na organização pessoal e nas atividades cotidianas dos idosos, sendo facilitadora da ampliação e manutenção de seu espaço de interação social.

O processo de autoconhecimento do seu corpo, a fruição artística e as trocas que acontecem entre diferentes subjetividades estabelecem um fluxo contínuo de aprendizado e reflexão que são fundamentais para o envelhecimento saudável. Essas experiências permitem ao idoso lidar com desabilidades funcionais e/ou sociais, ajudando-o na conquista de sua independência e autonomia através do encontro com novas possibilidades de relação consigo, sua família e comunidade.

$\mathrm{O}$ acesso a atividades culturais e as possibilidades de interação com a sociedade, através de sua produção artística, abrem novos caminhos para a consolidação de um papel social reconhecido, nos quais a produção artístico-cultural e intelectual dos idosos possa ser valorizada. Acessar a cultura implica, para o idoso, estar incluído e compartilhar esses valores culturais.

As atividades artísticas, aliadas aos preceitos da reabilitação psicossocial, podem ser pensadas como estratégias que promovam possibilidades de intermitência do sofrimento dos sujeitos idosos com seu envelhecimento e não determinem sua invalidação, mas possibilitem a recuperação de sua capacidade de gerar sentido e conseqüentemente valor social, restabelecendo sua contratualidade como cidadão.

Os projetos com atividades artísticas, aliados ao conhecimento em gerontologia mostram-se facilitadores para o estabelecimento de novas relações dos idosos com seu meio social, pois proporcionam possibilidades de ressignificação de sua experiência de envelhecimento através da criação plástica e estética. Podemos apontar como importante a sua apropriação de atividades sócioculturais da cidade em que vivem, podendo assim, construir um constante diálogo e trocas de seu mundo interno com o que os cercam.

LIMA, L. J. C. de; SILVEIRA, N. D. R. Views about aging: old age's distancing from and nearness to the big town. Rev. Ter. Ocup. Univ. São Paulo, v. 20, n. 3, p. 171-179, set./dez. 2009

\begin{abstract}
The contemporary globalization and urbanization processes together with the need to characterize the profile and needs of the growing number of elderly people all over the world have given a boost to recent interdisciplinary scientific investigations. In the work herein an attempt is made to provide contributions to the understanding of these issues by focusing on the elderly people who live in Sao Paulo City, SP, Brazil. It presents part of the results of a documental qualitative research that was based on the analysis of the content of works of art (paintings) and recorded oral statements both made by elderly people participating in a group of the Artistic Compositions and Occupational Therapy Permanent Program - PACTO - in the year 2001. Based on a conceptual field of interdisciplinary reference, and theorectically and empiracally considering the interfaces between Occupational Therapy, Art and Gerontology, it offers a reflection on the reality pointed out by these elderly: the measuring of their own biological aging is presented together with the consciousness of the reality they live with and the need to keep the affection, solidarity and care relations between aging people.
\end{abstract}

KEY WORDS: Aged. Art. Group processes. Occupational therapy. 


\section{REFERÊNCIAS}

CASTRO, E. D., et al. Habitando os campos da arte e da terapia ocupacional. Rev. Ter. Ocup. Univ. São Paulo, v. 13, n. 1, p. 18, 2002.

IBGE. Perfil dos Idosos responsáveis pelos domicílios. Disponível em: <http://www.ibge.gov.br> Acesso em: 26 jul. 2002.

JOLY, M. Introdução à análise da imagem. Campinas: Papirus, 1996.

JORDÃO NETTO, A., et al. Levantamento de algumas condições de vida da população de mais de 60 anos, moradora nas sedes das regiões metropolitanas do Brasil e Capital Federal. São Paulo, 1989/1992. (Mimeo)

LABORATÓRIO DE ESTUDOS E PESQUISAARTE E CORPO EM TERAPIA OCUPACIONAL. Caderno de anotações e relatos de grupos do Programa Permanente Composições Artísticas e Terapia Ocupacional. Centro de Docência e Pesquisa de Fonoaudiologia, Fisioterapia e Terapia Ocupacional. FMUSP, São Paulo, 2001. [Manuscrito].
LÜDKE, M.; ANDRÉ, M. E. D. A. Pesquisa em educação: abordagens qualitativas. São Paulo: Editora Pedagógica e Universitária, 1986.

MANGUEL, A. Lendo imagens. São Paulo: Companhia das Letras, 2001.

PASCHOAL, S. M. P. Autonomia e independência. In: CARVALHO FILHO, E. T.; PAPALÉO NETTO, M. (orgs.). Geriatria - fundamentos, clínica e terapêutica. São Paulo: Ateneu, 1994.

SIMÕES, R. (Qual) idade de vida na (qual) idade de vida. In: MOREIRA, W. W. (org.) Qualidade de vida: complexidade e educação. São Paulo: Papirus, 2001.

VERAS, R. Modelos contemporâneos de cuidado à saúde. Rev. Univ. São Paulo, n. 51, p. 72-85, set./nov. 2001.

WILHEIM, J. A paisagem descuidada. Caderno Mais!, Folha de São Paulo, 24 de agosto de 1997. p. 20. 